\title{
AVALIAÇÃO DE RESISTÊNCIA EM VARIEDADES DE ARROZ (Oryza sativa L.) AO ATAQUE DO Sitophilus oryzae LINNAEUS, 1763 (COLEOPTERA: CURCULIONIDAE)
}

\author{
SOUSA, Joseane Rodrigues ${ }^{1}$ \\ BARRIGOSSI, José Alexandre Freitas ${ }^{2}$ \\ BOIÇA JÚNIOR, Arlindo Leal ${ }^{3}$ \\ GONÇALVES, Keneson Klay Machado ${ }^{4}$ \\ TORRES, Érica Renyelle Silva ${ }^{5}$ \\ MONDEGO, Janaina Marques ${ }^{6}$
}

Recebido em: 2009.10 .25

Aprovado em: 2010.02.10

ISSUE DOI: $10.3738 / 1982.2278-314$

RESUMO: A resistência de variedades de arroz ao ataque do Sitophilus oryzae, Linnaeus, 1763 (Coleoptera: Curculionidae) foi avaliada em experimento conduzido em laboratório na Universidade Estadual do Maranhão, em delineamento experimental inteiramente casualizado com 19 tratamentos em seis repetições. As variedades utilizadas nesta pesquisa foram provenientes de experimento conduzido em campo no município de Miranda do Norte, MA entre os meses de janeiro a maio de 2006. Foram avaliados o total de insetos emergidos aos 35 e 60 dias após a colheita e aos 35 dias foi determinado o percentual de grãos com defeitos na casca. Os resultados evidenciaram que as variedades Agulha e Nenenzinho foram, respectivamente, nos dois períodos de armazenamento (35 e 60 dias após a colheita) as mais resistentes ao ataque de $S$. oryzae enquanto a variedade Branco Tardão foi a mais suscetível nos dois períodos de armazenamento.

Palavras-chave: Gorgulho do arroz. Grãos armazenados. Resistência de plantas.

\section{EVALUATION OF RESISTANCE IN VARIETIES OF RICE (Oryza sativa L.) TO ATTACK Sitophilus oryzae LINNAEUS, 1763 (COLEOPTERA: CURCULIONIDAE)}

SUMMARY: The resistance of rice varieties to the attack of Sitophilus oryzae Linnaeus, 1763 (Coleoptera: Curculionidae) was evaluated in an experiment conducted in the laboratory of the Universidade Estadual do Maranhão, in a randomized completely design with 19 treatments in six replications. The varieties used in this study were from field experiment conducted in Miranda do Norte, MA between the months of january to may 2006. We evaluated the emerged insects total at 35 and 60 days after harvest and at 35 days was determined the percentage of grains with defects in the skin. The results showed that the varieties Nenenzinho and Branco Tardão were, respectively, in the two storage periods (35 and 60 days after harvest) the most resistant to attack by $S$. oryzae as the variety Branco Tardão was the most susceptible in both storage of periods.

Keywords: Rice weevil. Stored grains, plant resistance.

\footnotetext{
${ }^{1}$ Fitossanidade Resistência de Plantas a Insetos. Universidade Estadual Paulista. joseaneagro@ yahoo.com.br

${ }^{2}$ Fitossanidade . Entomologia. Embrapa Arroz e Feijão. alex@ cnpaf.embrapa.br

${ }^{3}$ Fitossanidade. Resistência de Plantas a Insetos. Universidade Estadual Paulista. aboicajr@ fcav.unesp.br

${ }^{4}$ Fitossanidade . Universidade Estadual do Maranhão. kenesonk@yahoo.com.br

${ }^{5}$ Fitossanidade. Universidade Estadual do Maranhão. ericarenyelle@ hotmail.com

${ }^{6}$ Fitossanidade. Resistência de Plantas a Insetos. Universidade Estadual Paulista .

janainamondego@yahoo.com.br
} 


\section{INTRODUÇÃO}

Os insetos do gênero Sitophilus estão entre as pragas mais destrutivas no armazenamento. No Brasil, a espécie Sitophilus oryzae Linnaeus 1763 (Coleoptera: Curculionidae) popularmente conhecido como caruncho do milho destaca-se entre os insetos de maior importância para os grãos de arroz armazenados (VITAL et al., 2004) provocando perdas quantitativas e qualitativas (FONTES et al., 2003). Estima-se que no Brasil $20 \%$ da produção anual de grãos que está em torno de 120 milhões de toneladas, se perde entre a colheita e o armazenamento e que metade dessas perdas, é devido ao ataque de pragas durante o armazenamento (CAMPOS, 2005).

É encontrada em todas as regiões quentes e tropicais do mundo e são pragas primárias de arroz armazenado, podendo infestar os grãos no campo antes do armazenamento (FONTES et al, 2003). Na fase inicial os insetos se alimentam quase que exclusivamente do endosperma e depois do embrião, causando perda de peso e de nutrientes além de afetar o poder germinativo das sementes (PUZZI, 1986). Os insetos adultos caracterizam-se por apresentar elevado potencial biótico, possibilidade de ocorrência de infestação cruzada e pela capacidade de atacar e danificar um grande número de hospedeiro (GALLO et al., 2002).

A produção de arroz no Maranhão é predominantemente feita por agricultores com baixo grau técnico, de forma rudimentar, sem o uso de tecnologia apropriada, que utilizam o arroz como principal alimento da família e promovendo a venda do excedente produzido (MENDEZ DEL VILLAR et al., 2001). Apesar de existirem métodos modernos para armazenamento de grãos e controle de pragas desses produtos, o pequeno produtor maranhense vem utilizando determinadas técnicas tradicionais de armazenamento, a exemplo da panícula inteira em paióis e a do arroz trilhado de várias formas e guardado em caixas ou mesmo em sacarias.

O uso de variedades resistentes pode ser uma alternativa promissora de controle dessa praga devido à facilidade de utilização, não oneração do produto, ausência de contaminação dos grãos e compatibilidade com outros métodos de controle. Além de oferecer menos riscos para a saúde humana e animal (LARA, 1991). Estas condições são primordiais, principalmente para a agricultura que é praticada no estado do Maranhão, constituída na sua maioria de pequenos produtores que tem a cultura orizícola como principal alimento da família.

Para o desenvolvimento de variedades resistentes a insetos-pragas são necessários estudos sobre a detecção de genótipos que sirvam como fonte de resistência. Entretanto, 
existem poucas informações a respeito da resistência de variedades de arroz ao S. oryzae.

Na casca dos grãos de arroz a disposição da pálea e lema pode constituir causa de resistência ao $S$. oryzae durante o armazenamento, uma vez que grãos íntegros são menos atacados que aqueles com defeito na casca (fenda lateral ou ponta aberta) (LARA, 1991).

Esta pesquisa teve como objetivo determinar a resistência de 19 variedades de arroz cultivadas no estado do Maranhão submetidas ao ataque de $S$. oryzae.

\section{MATERIAL E MÉTODOS}

O experimento foi instalado no Laboratório de Entomologia do Núcleo de Biotecnologia Agronômica da Universidade Estadual do Maranhão entre os meses de maio a agosto 2006. As variedades utilizadas no presente estudo foram oriundas de plantio realizado em campo no município de Miranda do Norte, MA durante o mês de janeiro de 2006 e colhidas em maio de 2006. As variedades de arroz utilizadas nesta pesquisa foram adquiridas junto ao Banco de Germoplasma do Centro Nacional de Pesquisa de Arroz e FeijãoCNPAF/EMBRAPA situado em Santo Antônio de Goiás, GO. São elas: 1- Arroz Misturado; 2 - Agulha; 3 - Arroz do Governo; 4 - Arroz Comum; 5 - Branco Tardão; 6 - Bico Ganga; 7 Come Cru Vermelho; 8 - Cutião; 9 - Chatão; 10 - Desconhecido Branco; 11 - Gojoba 75 dias/Ligeiro; 12 - Matão; 13 - Marabá Branco; 14 - Nenenzinho; 15 - Pingo de Ouro; 16 Pingo D’água; 17 - Taboca; 18 - BR IRGA 409 e 19 - Vermelho.

O delineamento experimental foi inteiramente casualizado com 19 tratamentos em seis repetições. O experimento foi devidamente montado utilizando-se 114 recipientes plásticos com abertura de $11 \mathrm{~cm}$ de diâmetro e capacidade de $600 \mathrm{ml}$. Cada recipiente recebeu $68 \mathrm{~g}$ de grãos de cada variedade. Antes da pesagem e retirada das amostras foi verificado se o conteúdo de umidade das sementes de cada variedade encontrava-se em condições ótimas de armazenamento. Na tampa de cada recipiente plástico fez-se furos com estiletes de 0,05 mm para facilitar as trocas gasosas. Posteriormente, os recipientes foram devidamente etiquetados e colocados em sala climatizada com temperatura de $25^{\circ} \mathrm{C} \pm 2{ }^{\circ} \mathrm{C}$, umidade relativa de $70-80 \%$ e fotofase de $12 \mathrm{~h}$.

A resistência das variedades de arroz ao $S$. oryzae foi avaliada em dois períodos de armazenamento aos 35 e 60 dias após a colheita, realizando-se avaliações para determinar o total de insetos emergidos e o percentual de grãos com defeitos na casca. Para determinação do total de insetos emergidos, os grãos de todas as variedades foram peneirados e verificado e anotado o total de insetos emergidos. Quanto ao percentual de grãos com defeitos na casca 
este foi determinado apenas em um dos períodos de armazenamento aos 35 dias em 100 grãos retirados ao acaso de cada variedade e mensurados pela disposição da pálea e lema dos grãos de arroz de acordo com LARA (1991).

Os dados foram transformados em $(x+0,5)^{1 / 2}$ e submetidos à análise de variância com as médias comparadas pelo teste de Tukey a 5\% de probabilidade.

\section{RESULTADOS E DISCUSSÃO}

O efeito das variedades foi significativo $(\mathrm{P} \leq 0,05)$ em relação ao total de insetos emergidos nos dois períodos de armazenamento (35 e 60 dias), evidenciando a presença de variabilidade genética (Tabela 1).

Tabela 1. Total de insetos emergidos em dois períodos de armazenamento (35 e 60 dias) de $S$. oryzae, de dezenove variedades de arroz (Oryza sativa L.). São Luís, MA. 2006.

\begin{tabular}{|c|c|c|}
\hline \multirow[t]{2}{*}{ Variedades } & \multicolumn{2}{|c|}{ Insetos emergidos } \\
\hline & (35 dias) & (60 dias) \\
\hline Branco Tardão & $4,99 a$ & $7,99 a$ \\
\hline Gojoba 75 dias/Ligeiro & $3,93 \mathrm{ab}$ & $4,88 \mathrm{bc}$ \\
\hline Marabá Branco & $3,48 \mathrm{abc}$ & $3,92 \mathrm{bcd}$ \\
\hline Cutião & 3,39abc & $5,90 b$ \\
\hline Pingo D’água & $3,05 \mathrm{abc}$ & 4,29bcd \\
\hline Come Cru Vermelho & $2,82 \mathrm{abc}$ & $5,79 b$ \\
\hline Arroz do Governo & $2,66 \mathrm{abc}$ & $3,42 \mathrm{~cd}$ \\
\hline Chatão & $2,62 \mathrm{abc}$ & $3,42 \mathrm{~cd}$ \\
\hline Matão & $2,56 a b c$ & $3,94 \mathrm{bcd}$ \\
\hline BR IRGA 409 & $2,45 \mathrm{abc}$ & $4,72 \mathrm{bcd}$ \\
\hline Vermelho & $2,38 \mathrm{abc}$ & $3,22 \mathrm{~cd}$ \\
\hline Pingo de Ouro & $2,30 \mathrm{abc}$ & $3,92 \mathrm{bcd}$ \\
\hline Arroz Misturado & $2,19 \mathrm{abc}$ & 4,09bcd \\
\hline Nenenzinho & $2,06 b c$ & $2,88 \mathrm{~d}$ \\
\hline Taboca & $2,05 b c$ & $3,30 \mathrm{~cd}$ \\
\hline Desconhecido Branco & $2,00 \mathrm{bc}$ & $3,09 \mathrm{~cd}$ \\
\hline Bico Ganga & $1,95 b c$ & $3,78 \mathrm{~cd}$ \\
\hline Arroz Comum & $1,67 b c$ & $3,51 \mathrm{~cd}$ \\
\hline Agulha & $0,99 \mathrm{c}$ & $3,81 \mathrm{~cd}$ \\
\hline $\bar{F}$ (trat) & $2,60 * *$ & $10,21 * *$ \\
\hline CV (\%) & 51,72 & 22,54 \\
\hline
\end{tabular}

Médias não seguidas de mesma letra nas colunas diferem entre si pelo teste de Tukey. Dados transformados em $(x+0,5)^{1 / 2}$. ** Significativo a $5 \%$ de probabilidade.

As médias das variedades em relação à variável em estudo, aos 35 dias indicou que a variedade Agulha (0,99 insetos) foi a mais resistente quando comparada com as demais, uma vez que afetou negativamente o desenvolvimento das larvas, enquanto na variedade Branco Tardão (4,99 insetos) foi a mais suscetível comportando-se como mais favorável à 
emergência dos insetos proporcionando melhores condições para o desenvolvimento das larvas. Aos 60 dias foi constatado que nas variedades Nenenzinho emergiram 2,88 insetos e na Branco Tardão 7,99 insetos, comportando-se respectivamente, como resistente e suscetível frente ao ataque do S. zeamais (Tabela 1). De acordo com Lara (1991) o menor número de insetos emergidos em determinada variedade está associado a certo grau de resistência.

Estudos conduzidos por Marsaro Júnior et al. (2005) avaliaram a resistência de híbridos de milho ao ataque de $S$. zeamais, correlacionada com a presença de inibidores de amilase e com a composição nutricional dos grãos. Os autores concluíram que os inibidores de amilase presentes nos extratos de milho solúveis em tampão e etanol correlacionam-se negativa e significativamente com o índice de suscetibilidade, indicando que a presença desses inibidores contribuíram para a resistência dos híbridos de milho a S. zeamais.

A observação do percentual de grãos com defeitos na casca (Figura 1) permitiu identificar as variedades Marabá Branco, Vermelho e Come Cru Vermelho como as menos afetadas frente ao ataque do $S$. oryzae quando comparadas com as demais, enquanto as variedades Gojoba 75 dias/Ligeiro, Desconhecido Branco, Pingo de Ouro e Branco Tardão como as mais afetadas.

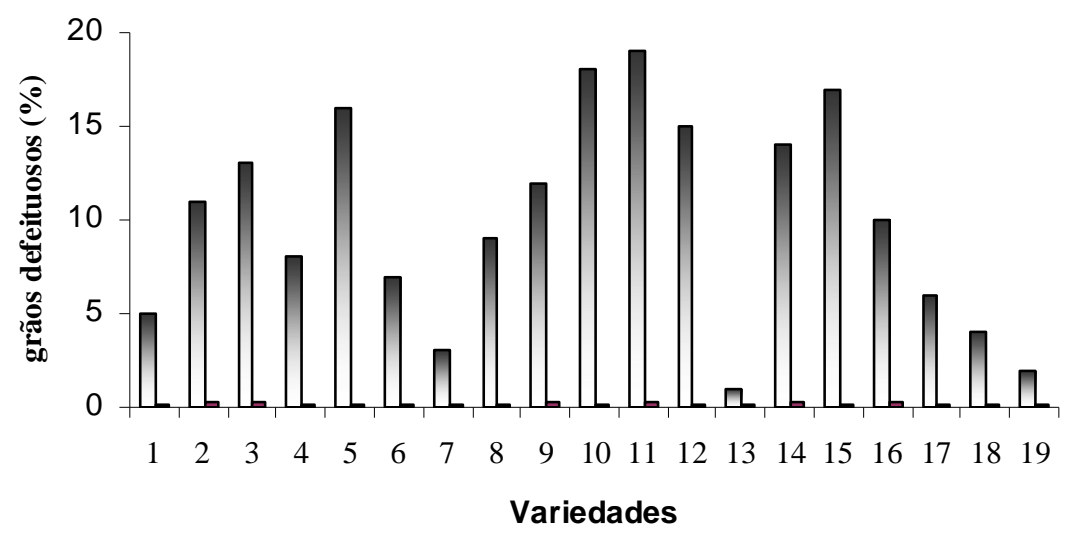

Figura 1. Percentual de grãos com defeitos na casca submetidos ao ataque do $S$. oryzae e mensurados pela disposição da pálea e lema dos grãos de arroz. São Luís, MA. 2006. Variedades: 1- Arroz Misturado; 2 - Agulha; 3 - Arroz do Governo; 4 - Arroz Comum; 5 Branco Tardão; 6 - Bico Ganga; 7 - Come Cru Vermelho; 8 - Cutião; 9 - Chatão; 10 Desconhecido Branco; 11 - Gojoba 75 dias/Ligeiro; 12 - Matão; 13 - Marabá Branco; 14 Nenenzinho; 15 - Pingo de Ouro; 16 - Pingo D'água; 17 - Taboca; 18 - BR IRGA 409 e 19 Vermelho.

Link et al (1971) avaliaram em condições de laboratório a resistência relativa de variedades de arroz em casca, ao ataque de S. oryzae (Linné, 1763), S. zeamais (Motschusky, 1855) e Sitotroga cerealella. Segundo os autores as variedades apresentaram frequiência elevada de grãos com defeitos na casca o que permitiu separa-los em dois grupos, um deles 
com grãos perfeitamente fechados pela casca e outro com cascas defeituosas sugerindo que a casca bem fechada é uma característica genética que pode conferir resistência a $S$. cerealella e outras pragas de grãos armazenados.

Os resultados dessa análise permitem fazer inferências sobre o comportamento das variedades em estudo, pois a análise em questão não apresenta uma boa concordância com os dados obtidos das médias dos insetos emergidos durante os dois períodos de armazenamento sugerindo que as variedades se comportam de maneira diferente e que, provavelmente devem existir outros fatores associados à resistência como, por exemplo, a dureza do grão. Na cultura do trigo essa característica pode influenciar fortemente a habilidade de S. oryzae em se reproduzir (MCGAUGHEY et al., 1990). Dessa forma, sementes de diferentes variedades podem apresentar diversos níveis de resistência a insetos de grãos armazenados.

Nunes (1989), estudaram a resistência de cultivares de arroz CICA 8, CICA 4 e

Metica 1 recomendadas para o cultivo de sequeiro ao Sitophilus spp. no estado do Piauí e observaram que as cultivares CICA 8 e CICA 4 emergiram 2 e 9 insetos respectivamente, enquanto na cultivar Metica 1 emergiram 398 indivíduos; e que quanto maior o potencial de defeitos na casca, maior a suscetibilidade da cultivar.

\section{CONCLUSÃO}

A variedade Agulha e Nenenzinho foram, respectivamente, nos dois períodos de armazenamento (35 e 60 dias após a colheita) as mais resistentes ao ataque de $S$. oryzae enquanto a variedade Branco Tardão foi a mais suscetível nos dois períodos de armazenamento.

\section{REFERÊNCIAS}

CAMPOS, T. B. Pragas dos grãos armazenados., In: REUNIÃO ITINERANTE DE FITOSSANIDADE DO INSTITUTO BIOLÓGICO - PRAGAS AGROINDUSTRIAIS. Anais... p.93. Ribeirão Preto, SP, 2005.

FONTES, L. S.; ALMEIDA FILHO, A. J.; ARTHUR, V. Danos causados por Sitophilus oryzae (Linné, 1763) e Sitophilus zeamais Motschulsky, 1855 (Coleoptera: Curculionidae) em cultivares de arroz (Oryza sativa L.). Arquivos do Instituto Biológico, São Paulo, v. 70, n. 3, p.303-307, 2003.

GALLO, D.et al. Manual de entomologia agrícola. Piracicaba: FEALQ, 2002. 920p. 
LARA, F. M. Princípios de resistência de plantas aos insetos. 2.ed. São Paulo: Ícone, 1991. p.336.

LINK, D.; ROSSETO, C. J.; IGUE, T. Resistência relativa de variedades de arroz em casca, ao ataque de Sitophilus oryzae (Linné, 1763), S. zeamais Motschusky, 1855 e Sitotroga cerealella (Olivier, 1819) em condições de laboratório. Santa Maria: Universidade Federal de Santa Maria, 1971. 70p. (Boletim Técnico, 2).

MARSARO JÚNIOR, A. L.et al. Inibidores de amilase em híbridos de milho como fator de resistência a Sitophilus zeamais (Coleoptera: Curculionidae). Neotropical Entomology, Londrina, v. 34, n. 3, p. 443-450, 2005.

McGAUGHEY, W. H.; SPEIRS, R. D.; MARTIN, C. R. Susceptibility of classes of wheat grown in the United States to stored-grain insects. Journal of Economic Entomology, Baltimore, v. 83, p.1122-1127, 1990.

MENDEZ DEL VILLAR, P.et al. Cadeia produtiva do arroz no estado do Maranhão. Teresina, EMBRAPA - Meio Norte, 136p, 2001.

NUNES, R. C. F. Resistência de cultivares de arroz recomendadas para o cultivo do arroz irrigado e sequeiro no Piauí ao gorgulho Sitophilus spp. (Coleoptera,

Curculionidae). 1989. 20p. Monografia - Universidade Federal do estado do Piauí. Teresina.

PUZZI, D. Abastecimento e armazenagem de grãos. São Paulo: Instituto Campineiro de Ensino Agrícola, 1986. 1917p.

VITAL, M. V. C. et al. Insetos em experimentos de ecologia de populações: um exemplo de abordagem didática. Acta Scientiarum, Maringá, v. 26, n. 3, p. 287-290, 2004. 
